City University of New York (CUNY)

CUNY Academic Works

\title{
Network Structure of Vertebrate Scavenger Assemblages at the Global Scale: Drivers and Ecosystem Functioning Implications
}

\author{
Esther Sebastián-González \\ Universidad Miguel Hernandez de Elche \\ Zebensui Morales-Reyes \\ Universidad Miguel Hernandez de Elche \\ Francisco Botella \\ Universidad Miguel Hernandez de Elche \\ Lara Naves-Alegre \\ Universidad Miguel Hernandez de Elche \\ Juan M. Pérez-García \\ Universidad Miguel Hernandez de Elche
}

See next page for additional authors

\section{How does access to this work benefit you? Let us know!}

More information about this work at: https://academicworks.cuny.edu/qc_pubs/392

Discover additional works at: https://academicworks.cuny.edu

This work is made publicly available by the City University of New York (CUNY).

Contact: AcademicWorks@cuny.edu 


\section{Authors}

Esther Sebastián-González, Zebensui Morales-Reyes, Francisco Botella, Lara Naves-Alegre, Juan M.

Pérez-García, Patricia Mateo-Tomás, Pedro P. Olea, Marcos Moleón, Jomar M. Barbosa, Fernando Hiraldo, Eneko Arrondo, José A. Donázar, Ainara Cortés-Avizanda, Nuria Selva, Sergio A. Lambertucci, Aishwarya Bhattacharjee, Alexis L. Brewer, Erin F. Abernethy, Kelsey L. Turner, James C. Beasley, Travis L. DeVault, Hannah C. Gerke, Olin E. Rhodes Jr, Andrés Ordiz, Camilla Wikenros, Barbara Zimmermann, Petter Wabakken, Christopher C. Wilmers, Justine A. Smith, Corinne Kendall, Darcy Ogada, Ethan Frehner, Maximilian L. Allen, Heiko U. Wittmer, James R. A. Butler, Johan T. du Toit, Antoni Margalida, Pilar OlivaVidal, David Wilson, Klemen Jerina, Miha Krofel, Rich Kostecke, Richard Inger, Esra Per, Yunus Ayhan, Hasan Ulusoy, Doğanay Vural, Akino Inagaki, Shinsuke Koike, Arockianathan Samson, Paula L. Perrig, Emma Spencer, Thomas M. Newsome, Marco Heurich, José D. Anadón, Evan R. Buechley, and José A. Sánchez-Zapata 


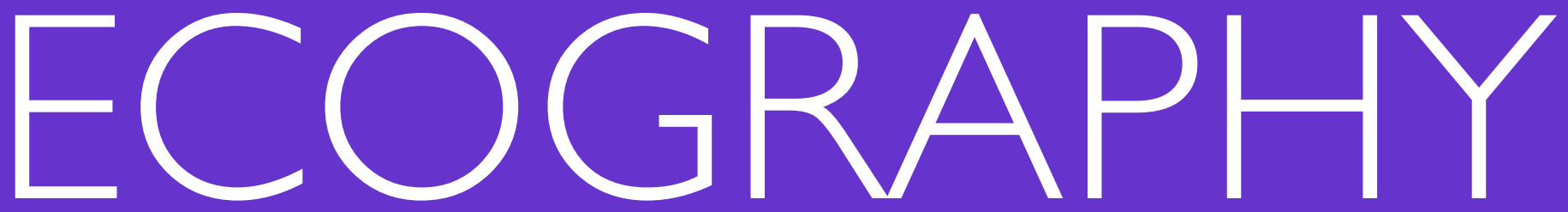

Research

\title{
Network structure of vertebrate scavenger assemblages at the global scale: drivers and ecosystem functioning implications
}

\author{
Esther Sebastián-González, Zebensui Morales-Reyes, Francisco Botella, Lara Naves-Alegre, \\ Juan M. Pérez-García, Patricia Mateo-Tomás, Pedro P. Olea, Marcos Moleón, Jomar M. Barbosa, \\ Fernando Hiraldo, Eneko Arrondo, José A. Donázar, Ainara Cortés-Avizanda, Nuria Selva, \\ Sergio A. Lambertucci, Aishwarya Bhattacharjee, Alexis L. Brewer, Erin F. Abernethy, Kelsey L. Turner, \\ James C. Beasley, Travis L. DeVault, Hannah C. Gerke, Olin E. Rhodes Jr, Andrés Ordiz, Camilla Wikenros, \\ Barbara Zimmermann, Petter Wabakken, Christopher C. Wilmers, Justine A. Smith, Corinne J. Kendall, \\ Darcy Ogada, Ethan Frehner, Maximilian L. Allen, Heiko U. Wittmer, James R. A. Butler, Johan T. du Toit, \\ Antoni Margalida, Pilar Oliva-Vidal, David Wilson, Klemen Jerina, Miha Krofel, Rich Kostecke, \\ Richard Inger, Esra Per, Yunus Ayhan, Hasan Ulusoy, Doğanay Vural, Akino Inagaki, Shinsuke Koike, \\ Arockianathan Samson, Paula L. Perrig, Emma Spencer, Thomas M. Newsome, Marco Heurich, \\ José D. Anadón, Evan R. Buechley and José A. Sánchez-Zapata
}

E. Sebastián-González (https://orcid.org/0000-0001-7229-1845) অ (esebgo@gmail.com), Z. Morales-Reyes (https://orcid.org/0000-0002-4529-8651), F. Botella, L. Naves-Alegre, J. M. Pérez-García and J. A. Sánchez-Zapata, Dept of Applied Biology, Univ. Miguel Hernández, Elche, Spain. - P. MateoTomás (https://orcid.org/0000-0001-6762-9514), Biodiversity Research Unit (UMIB), UO-CSIC-PA, Oviedo Univ., Mieres, Spain, and Centre for Functional Ecology, Dept of Life Sciences, Univ. of Coimbra, Coimbra, Portugal. - P. P. Olea, Depto de Ecología, Univ. Autónoma de Madrid, Madrid, Spain, and Centro de Investigación en Biodiversidad y Cambio Global (CIBC-UAM), Univ. Autónoma de Madrid, Madrid, Spain. - M. Moleón, Dept of Zoology, Univ. of Granada, Granada, Spain. - J. M. Barbosa, F. Hiraldo, E. Arrondo, J. A. Donázar and A. Cortés-Avizanda, Dept of Conservation Biology, Doñana Biological Station-CSIC, Seville, Spain. AC-A also at: Animal Ecology and Demography Group, IMEDEA (CSIC-UIB), Esporles, Spain. N. Selva, Inst. of Nature Conservation, Polish Academy of Sciences, Krakow, Poland. - S. A. Lambertucci, Grupo de Investigaciones en Biología de la Conservación, Laboratorio Ecotono, INIBIOMA (CONICET, Univ. Nacional del Comahue), Bariloche, Argentina. - A. Bhattacharjee, A. L. Brewer and J. D. Anadón, Dept of Biology, Queens College, City Univ. of New York, Queens, NY, USA, and Biology Program, The Graduate Center, City Univ. of New York, New York, NY, USA. JDA also at: Depto de

Ecography

43: $1-13,2020$

doi: $10.1111 /$ ecog.05083

Subject Editor and

Editor-in-Chief: Migel Araújo

Accepted 8 April 2020

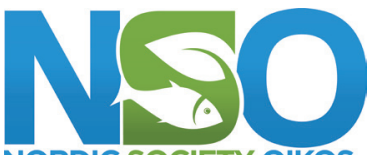

NORDIC SOCIETY OIKOS

www.ecography.org
Ciencias Agrarias y el Medio Natural, Univ. de Zaragoza. Huesca, Spain. - E. F. Abernethy (https:/lorcid. org/0000-0002-9197-3531), Dept of Integrative Biology, Oregon State University, Corvallis, OR, USA. K. L. Turner, J. C. Beasley, T. L. DeVault and H. C. Gerke, Savannah River Ecology Lab, Warnell School of Forestry and Natural Resources, Univ. of Georgia, Aiken, SC, USA. - O. E. Rhodes Jr, Savannah River Ecology Laboratory, Odum School of Ecology, Univ. of Georgia, Aiken, SC, USA. - A. Ordiz, Faculty of Environmental Sciences and Natural Resource Management, Norwegian Univ. of Life Sciences, As, Norway. - C. Wikenros, Grimsö Wildlife Research Station, Dept of Ecology, Swedish Univ. of Agricultural Sciences, Riddarhyttan, Sweden. - B. Zimmermann and P. Wabakken, Faculty of Applied Ecology, Agricultural Sciences and Biotechnology, Campus Evenstad, Inland Norway Univ. of Applied Sciences, Norway. - C. C. Wilmers, Center for Integrated Spatial Research, Environmental Studies Dept, Univ. of California, Santa Cruz, CA, USA. - J. A. Smith (https://orcid.org/0000-0001-8753-4061), Dept of Wildlife, Fish, and Conservation Biology, Univ. of California, Davis, CA, USA. - C. J. Kendall (https:/l orcid.org/0000-0003-4429-4496), North Carolina Zoo, Asheboro, NC, USA. - D. Ogada, The Peregrine Fund, Boise, ID, USA. - E. Frehner, Dept of Biology, Univ. of Utah, Salt Lake City, UT, USA. - M. L. Allen, Illinois Natural History Survey, Univ. of Illinois, Champaign, IL, USA. - H. U. Wittmer, School of Biological Sciences, Victoria Univ. of Wellington, Wellington, New Zealand. - J. R. A. Butler, CSIRO Land and Water, Brisbane, QLD, Australia. - J. T. du Toit, Dept of Wildland Resources, Utah State Univ., Logan, UT, USA. - A. Margalida, P. Oliva-Vidaland JMP-G, Dept of Animal Science, Faculty of Life Sciences and Engineering, Univ. of Lleida, Lleida, Spain. AM also at: Inst. de Investigación en Recursos

(C) 2020 The Authors. Ecography published by John Wiley \& Sons Ltd on behalf of Nordic Society Oikos This is an open access article under the terms of the Creative Commons Attribution License, which permits use, distribution and reproduction in any medium, provided the original work is properly cited. 
Cinegéticos (IREC, CSIC-UCLM-JCCM), Ciudad Real, Spain. - D. Wilson, The Biodiversity Consultancy, Cambridge, UK. - K. Jerina and M. Krofel, Biotechnical Faculty, Univ. of Ljubljana, Ljubljana, Slovenia. - R. Kostecke, The Nature Conservancy, Austin, TX, USA. - R. Inger, Environment and Sustainability Inst., Univ. of Exeter, Penryn, UK. - E. Per, Faculty of Science, Dept of Biology, Gazi Univ., Teknikokullar, Ankara, Turkey. - Y. Ayhan, H. Ulusoy, D. Vural and EP, DEDE Nature Team, Yenimahalle Ankara, Turkey. - A. Inagaki and S. Koike, Dept of Environment Conservation, Tokyo Univ. of Agriculture and Technology, Fuchu, Tokyo, Japan. - A. Samson, Bombay Natural History Society, Mumbai, India. - P. L. Perrig, Dept of Forest and Wildlife Ecology, Univ. of Wisconsin-Madison, WI, USA. - E. Spencer and T. M. Newsome, School of Life and Environmental Sciences, The Univ. of Sydney, Sydney, Australia. - M. Heurich, Dept of Visitor Management and National Park Monitoring, Bavarian Forest National Park, Grafenau, Germany, and Chair of Wildlife Ecology and Management, Univ. of Freiburg, Freiburg, Germany. - E. R. Buechley (https://orcid.org/0000-0001-51804824), Smithsonian Migratory Bird Center, Washington, DC, USA, and HawkWatch International, Salt Lake City, UT, USA.

The organization of ecological assemblages has important implications for ecosystem functioning, but little is known about how scavenger communities organize at the global scale. Here, we test four hypotheses on the factors affecting the network structure of terrestrial vertebrate scavenger assemblages and its implications on ecosystem functioning. We expect scavenger assemblages to be more nested (i.e. structured): 1) in species-rich and productive regions, as nestedness has been linked to high competition for carrion resources, and 2) regions with low human impact, because the most efficient carrion consumers that promote nestedness are large vertebrate scavengers, which are especially sensitive to human persecution. 3) We also expect climatic conditions to affect assemblage structure, because some scavenger assemblages have been shown to be more nested in colder months. Finally, 4) we expect more organized assemblages to be more efficient in the consumption of the resource. We first analyzed the relationship between the nestedness of the scavenger assemblages and climatic variables (i.e. temperature, precipitation, temperature variability and precipitation variability), ecosystem productivity and biomass (i.e. NDVI) and degree of human impact (i.e. human footprint) using 53 study sites in 22 countries across five continents. Then, we related structure (i.e. nestedness) with its function (i.e. carrion consumption rate). We found a more nested structure for scavenger assemblages in regions with higher NDVI values and lower human footprint. Moreover, more organized assemblages were more efficient in the consumption of carrion. However, our results did not support the prediction that the structure of the scavenger assemblages is directly related to climate. Our findings suggest that the nested structure of vertebrate scavenger assemblages affects its functionality and is driven by anthropogenic disturbance and ecosystem productivity worldwide. Disarray of scavenger assemblage structure by anthropogenic disturbance may lead to decreases in functionality of the terrestrial ecosystems via loss of key species and trophic facilitation processes.

Keywords: carrion, consumption rate, ecological networks, global change, macroecology, NDVI

\section{Introduction}

Community structure is a key determinant of ecosystem functioning (Hooper et al. 2005, Bannar-Martin et al. 2017), biodiversity conservation (Tylianakis et al. 2010) and community stability (Landi et al. 2018). In turn, the nonrandom structure of communities (Guillemot et al. 2011, de Miguel et al. 2016) is driven by numerous biological, ecological, anthropogenic and evolutionary forces (Dalsgaard et al. 2013, Martín-González et al. 2015, Ley et al. 2017). Thus, disentangling the factors affecting the organization of ecological communities is essential for understanding ecosystem functioning and prioritizing conservation efforts.

The structure of animal and plant communities can be characterized in different ways (Verhoef and Morin 2010). Traditionally, studies have focused on describing species composition and richness, but in the last few decades, analytical approaches that provide additional information have gained the attention of ecologists. Network analyses summarize communities and assemblages numerically, making community structure statistically comparable (Bascompte and Jordano 2013). Networks have thus been widely used to compare the structure of ecological communities at the global scale (Dalsgaard et al. 2013, Schleuning et al. 2014, Song et al. 2017), and several studies have revealed that the structure of ecological networks may be affected by global-scale factors such as current and past climate (Martín-González et al. 2015, Sebastián-González et al. 2015, Song et al. 2017, Albouy et al. 2019, Mendoza and Araújo 2019), or human impact (Sebastián-González et al. 2015, Mendoza and Araújo 2019). However, the effect of each factor is contingent upon the type of ecological assemblage under study (e.g. it is different for seed-dispersal and for pollination assemblages, Sebastián-González et al. 2015, Song et al. 2017). Thus, it is important to identify the processes driving these large-scale patterns for different types of assemblages.

Terrestrial vertebrate scavengers (i.e. carrion consumers) are key providers of ecosystem functions as they regulate disease and pest expansion, accelerate the cycling of nutrients, and stabilize food webs (Beasley et al. 2019). Moreover, supplanting these ecosystem services provided by scavengers requires costly carcass collection and transportation (Morales-Reyes et al. 2015). However, the efficiency of the scavenging assemblage at consuming carrion varies widely depending on factors such as scavenger species richness, composition and abundance (Mateo-Tomás et al. 2017), vegetation type (Turner et al. 2017), temperature (DeVault et al. 2004), human impact (Huijbers et al. 2015), or carcass characteristics (i.e. size; Selva et al. 2005, Moleón et al. 2015). In addition, most studies that attempt to disentangle the 


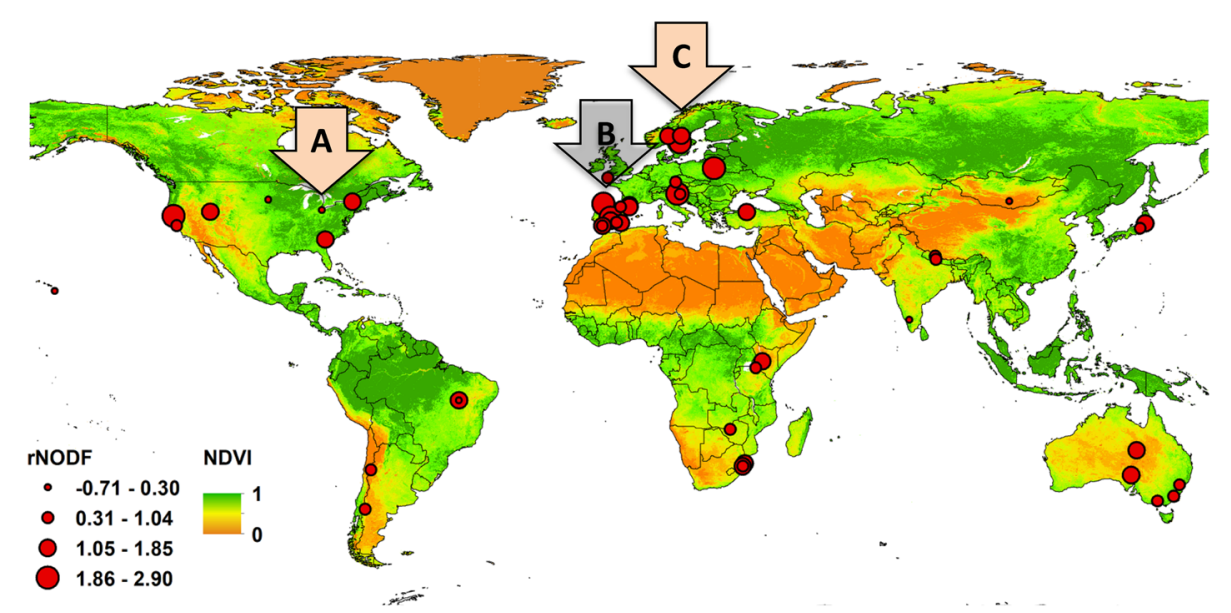

(A) Random

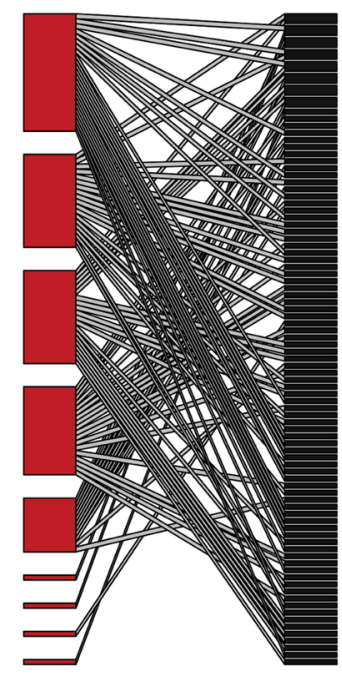

(B) Nested

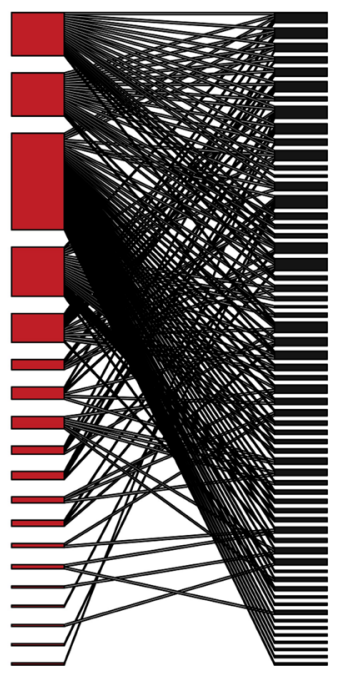

(C) Nested (weighted)

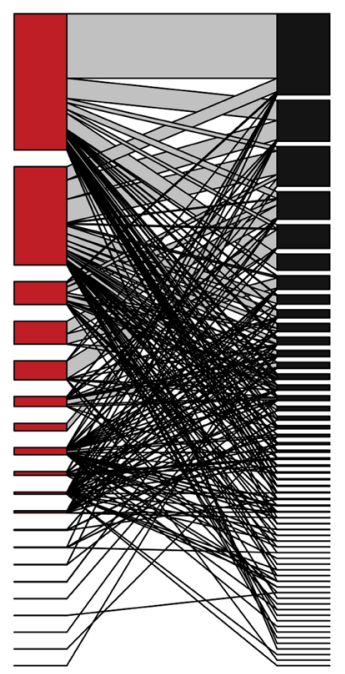

Figure 1. Map showing the origin of the data included in this study, where each point represents one study site and the size of the point is related to its nestedness value (rNODF). We also show bipartite graphs representing three of our networks describing scavenger assemblages that are (A) random (i.e. not nested), (B) nested and (C) nested (with weighted data). Each red rectangle represents a scavenger species and each black rectangle represents a carcass. The size of the rectangle is related to the number of times a species appears in the network as consumer (in A and B) or abundance (in C). The lines match scavenger species consuming a specific carcass, and the width of the line for the weighted nestedness represents the number of individuals consuming that specific carcass.

factors driving scavenger assemblages have focused on small spatial scales with only one or a few study sites (Selva and Fortuna 2007, Turner et al. 2017). Recently, in a global study, Sebastián-González et al. (2019) found the number of scavenger species in an assemblage was related to the degree of human impact, with fewer scavenger species found in areas with higher human impacts. However, our understanding of the factors driving the structure of these assemblages at the global scale is still very limited.

Here, we use network analyses and the largest compilation of data to date on vertebrate scavenger assemblages at the global scale (53 studies across five continents, Fig. 1, Supplementary material Appendix 1) to identify the effects of macroecological factors in structuring vertebrate scavenger assemblages. We focus on nestedness, a feature of community organization that has already been used to describe scavenger assemblages (Selva and Fortuna 2007). In a nested assemblage, the species feeding on carcasses visited by few consumers are subsets of those species feeding on carcasses visited by more consumers. In scavenging assemblages, this pattern can emerge through facilitation, when the use of carrion by some species facilitates its use by others, such as hyaenas tearing through tough skin and thereby opening a large carcass for smaller scavengers (Álvarez et al. 1976, Kane and Kendall 2017). Previous studies evaluating the network structure of vertebrate scavenger assemblages have found a more nested organization of those assemblages featuring greater competition for resources. This can occur for example during the cold season when food resources are more valuable (Selva and Fortuna 2007), in assemblages with specialized (e.g. vultures, 
Sebastián-González et al. 2016) or dominant (e.g. black bears Ursus americanus, Allen et al. 2014) scavengers that can monopolize resources, or where predators provide a relatively constant supply of carrion to compete for (Selva and Fortuna 2007). Thus, we expect that the structure of scavenger assemblages will be affected by climatic conditions (i.e. seasonality, temperature and precipitation), because they affect food availability (Hypothesis I, Table 1). Alternatively, because more productive regions tend to have higher animal species richness at a global scale (Bailey et al. 2004, Cusens et al. 2012), we might expect assemblages in highly productive regions to be more nested because of higher interspecific competition for resources (Hypothesis II, Table 1). We also expect assemblages in regions with greater human impact to be less nested than assemblages in less disturbed areas (Hypothesis III, Table 1), due to the loss of large vertebrate scavengers, which are functionally dominant through their efficiency at consuming carrion, but are especially sensitive to anthropogenic threats (Mateo-Tomás et al. 2017, Fig. 2). Finally, we also tested if the structure of the assemblage (i.e. nestedness) was related to its function (i.e. carrion consumption rate; Hypothesis IV, Table 1). As in a previous study (SebastiánGonzález et al. 2016) we expect more nested assemblages to have greater carcass consumption rates.

\section{Methods}

\section{Dataset}

We compiled information from 53 studies in 22 countries across five continents (Fig. 1, Supplementary material Appendix 1) to describe the structure of terrestrial vertebrate scavenger assemblages using 2629 carcasses (mean number of carcasses per study \pm SD: $49.6 \pm 53.6$; range: $6-267)$. We monitored the vertebrate species consuming herbivore carcasses of a wide size range (from rodents and birds weighing $<0.01 \mathrm{~kg}$ to ungulates weighing $>100 \mathrm{~kg}$ ), mainly using automatic camera traps (47 out of the 53 studies) with standardized protocols (Rovero and Zimmerman 2016). The remaining six studies were based on either direct sighting from sufficient distances to minimize scavenger avoidance, or from indirect signs of scavenger interaction with the carcass (Selva and Fortuna 2007). All carcasses were either fresh, had been frozen while fresh prior to placement in the field, or were prey remains after predator kills. They were continuously monitored until only bones and/or skin remained in the field or the carcass was removed by a scavenger. Data were gathered between 1991 and 2019.

For each study site, we collected information on which vertebrate scavengers fed on a monitored carcass (only species that were confirmed to consume carrion were included in this study). For 47 of the 53 datasets for which quantitative information was available, we computed scavenger relative abundance as the maximum number of unequivocally different individuals of each species detected scavenging at each carcass. This was calculated by identifying the maximum number of individuals of a scavenger species simultaneously appearing in a picture or observation throughout the duration of the trial, or by identifying unequivocally different individuals from the same species using distinct marks, color patterns, age/sex differences, etc. (Moleón et al. 2015, MateoTomás et al. 2017).

Carcass monitoring was summarized at each study site by constructing a matrix where carcass $i$ was represented by rows and scavenging species $j$ by columns. We first analyzed qualitative information (i.e. species occurrence at a carcass) where each matrix element $a_{i j}$ indicated whether scavenger species $j$ had been detected consuming carcass $i$ or not (scored 1 or 0 ). Also, for the weighted matrices, each matrix element $a_{i j}$ was filled with the number of different individuals of each species detected at a single carcass (i.e. scavenger relative abundance).

For each carcass, we also calculated carcass depletion time as the total time (in hours) required to completely consume or remove each carcass since it was located or placed in the field. We considered it fully consumed when only parts of the skeleton were left or if taken away from the camera focus by a large scavenger (Moleón et al. 2015). In the last case, we only considered carcasses in which the part taken was small enough to be consumed completely by the scavenger. Then, we calculated the average depletion time at each site, and estimated the carcass consumption rate as the kilogram of carcass consumed per hour by dividing the average carcass weight by the average depletion time. We only calculated the carcass consumption rate for those sites that were monitored with camera traps to avoid biases.

\section{Measuring network structure}

We measured network structure using nestedness, which can be calculated both with occurrence and abundance (called weighted nestedness) data. We first calculated the nestedness of the assemblage at each study site based on species occurrences using the metric NODF (nestedness overlap and decreasing fills; Almeida-Neto et al. 2008), then weighted nestedness based on relative abundances of individuals of each species using the metric weighted NODF (WNODF; Almeida-Neto and Ulrich 2011). These metrics estimate the degree of nestedness of the matrix, ranging from 0 to 100 (i.e. perfectly nested).

All network metrics must be normalized for comparison. To do so, we compared the observed value of each matrix with the values of matrices constructed following a null model. The null model for NODF controls for the effects of species richness, number of sampled carcasses, and keeps the heterogeneity in the number of interactions across species and carcasses. In the null model for WNODF, the probability that a species consumes a carcass or that a carcass is consumed are proportional to the number of carcasses where the species was detected and the number of individuals of each species detected consuming each carcass, respectively. We used 1000 simulations for both metrics. We normalized the nestedness values following Montesinos-Navarro et al. (2017) as: 
Table 1. Summary of the stated biogeographical hypotheses, expected pattern, the underlying processes behind it and the main supporting references. NDVI: normalized difference vegetation index, HF: human footprint.

\begin{tabular}{|c|c|c|c|}
\hline Hypothesis & Expected pattern & Underlying processes & Main references \\
\hline I & $\begin{array}{l}\text { Network structure will be } \\
\text { related to climatic } \\
\text { conditions (i.e. seasonality, } \\
\text { temperature and } \\
\text { precipitation) }\end{array}$ & $\begin{array}{l}\text { There is a more nested organization in cold seasonal } \\
\text { regions where there is greater competition for resources } \\
\text { due to limited food availability. } \\
\text { When temperature and humidity are high, decomposers } \\
\text { can monopolize some carcasses, affecting vertebrate } \\
\text { scavenger's structure. }\end{array}$ & $\begin{array}{l}\text { Selva and Fortuna } 2007 \\
\text { DeVault et al. } 2011 \\
\text { Allen et al. } 2014 \\
\text { Ray et al. } 2014 \\
\text { Sebastián-González et al. } 2016\end{array}$ \\
\hline II & $\begin{array}{l}\text { Increase in nestedness with } \\
\text { an increase in productivity } \\
\text { and biomass (i.e. NDVI) }\end{array}$ & $\begin{array}{l}\text { There is a more nested organization in productive regions } \\
\text { where scavenger rich assemblages promote higher inter } \\
\text { specific competition for resources and facilitation } \\
\text { processes. }\end{array}$ & $\begin{array}{l}\text { Bailey et al. } 2004 \\
\text { Selva and Fortuna } 2007 \\
\text { Cusens et al. } 2012 \\
\text { Allen et al. } 2014 \\
\text { Moleón et al. } 2014 \\
\text { Sebastián-González et al. } 2016\end{array}$ \\
\hline III & $\begin{array}{l}\text { Decrease in nestedness with } \\
\text { an increase in human } \\
\text { impact (i.e. HF) }\end{array}$ & $\begin{array}{l}\text { The species lost more rapidly from the scavenger } \\
\text { assemblage due to anthropogenic threats are those that } \\
\text { consume carrion faster and promote nestedness (e.g. } \\
\text { vultures, large carnivores). }\end{array}$ & Mateo-Tomás et al. 2017 \\
\hline
\end{tabular}

$\operatorname{rMETRIC}=($ value $-\operatorname{mean}($ null model $)) / \operatorname{mean}($ null model $)$

where mean(null model) is the mean of all the metric values calculated using each null model. We refer to these metrics as relative nestedness (rNODF) and relative weighted nestedness (rWNODF).
We included matrix size (i.e. the total number of columns and rows in each study) and connectance (i.e. the proportion of realized interactions in relation to the total number of possible interactions) as covariates in our models (see Statistical analyses) to control for the effects of these network properties on nestedness values (Fortuna et al. 2010, Song et al. 2017). We calculated nestedness

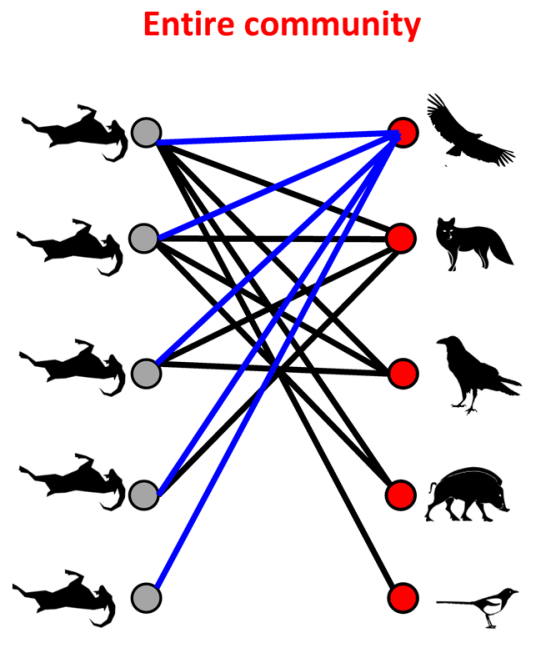

(Nested)
Key species lost

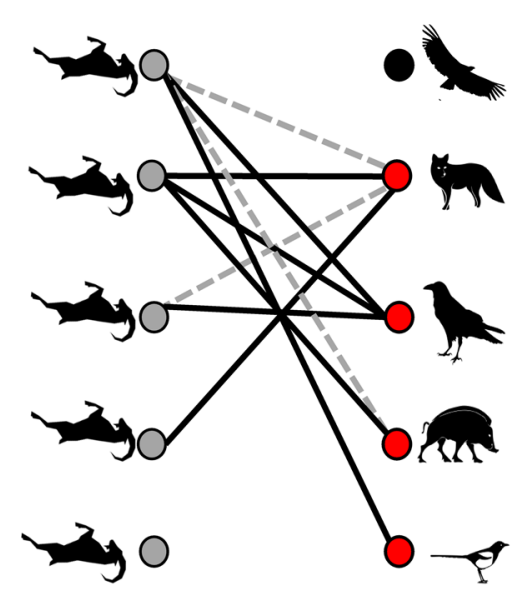

(Not nested)

Figure 2. Conceptual representation on how the loss of key species due to human impact may affect the structure of the network. Red circles represent scavenger species and grey circles individual carcasses. Solid connecting lines indicate that a scavenger species was detected consuming a specific carcass. Dashed grey lines represent secondary lost interactions caused by the loss of other species. The left graph represents a hypothetical perfectly nested assemblage and the blue lines show all the carcasses consumed by a key scavenger species (here, a vulture). On the right graph the vulture is lost due to human impacts, having several consequences on the network: First, the upper and middle carcasses are no longer available to some of the other consumers (e.g. because their skin is very thick and some species are unable to open and consume it). Second, the carcass at the bottom of the network is no longer consumed by vertebrates (and will then be consumed by invertebrates and decomposers, which are slower). Consequently, the structure of the assemblage is no longer nested. Silhouettes from The Noun Project <https://thenounproject.com>, authors: S. Laing, A. Bearne, M. Turan Ercan, H. Richir, Bluetip Design and P. Lehmann. 
values with the 'bipartite' package of $\mathrm{R}$ (Dormann et al. 2009).

\section{Macroecological variables}

For each site, we calculated six macroecological variables (see Table 2 for details) related to our hypotheses. Some of these variables were selected because 1) they characterize the climatic conditions of a region: mean annual temperature $\left({ }^{\circ} \mathrm{C}\right)$, temperature seasonality, mean annual precipitation $(\mathrm{mm})$ and precipitation seasonality; 2) they are related to resource availability: normalized difference vegetation index (NDVI), a proxy of the primary productivity and biomass; or 3) they represent the degree of human impact: human footprint (HF), an indicator of human population pressure, human land use and infrastructure, and human access. HF has been calculated for two years, so we assigned to each study site the HF value closest to the date when the study was performed: $1993(\mathrm{n}=3)$ and $2009(\mathrm{n}=50)$.

We calculated these variables within a $20 \mathrm{~km}$ buffer radius around the coordinates of each study site to represent site conditions where carcasses were located. This 125664 ha sampling area also represents habitat characteristics of the study areas where sites were located, at a biogeographical scale that minimizes dilution from nearby areas with different land uses (mean size \pm SD of study sites: $106324 \pm 297867$ ha; see Supplementary material Appendix 1 for the sizes of all study sites). Most of these variables derived from a model and have a large spatial resolution, so we did not expect them to show substantial variability among scales. However, we also calculated all variables using 10 and $30 \mathrm{~km}$ buffers around the center of each study site to determine the spatial consistency of our results at smaller and larger resolutions, respectively. We then correlated each of the variables at the three spatial scales (e.g. temperature at 10 versus $20 \mathrm{~km}, 10$ versus $30 \mathrm{~km}$, 20 versus $30 \mathrm{~km}$ ) to assess their potential variability using Pearson correlations.

\section{Statistical analyses}

Previous studies indicate that some variables, such as carcass weight, presence of obligate scavengers and spatial autocorrelation, may influence scavenger assemblage structure. Large carcasses are consumed by more nested scavenger assemblages (Moleón et al. 2015), thus we included the average weight of monitored carcasses (in $\mathrm{kg}$ ) at each study site as a covariate in the model. Assemblages of obligate scavengers, such as vultures, are also known to be more nested (SebastiánGonzález et al. 2016), so we also included the presence of obligate scavengers as a covariate. Finally, to account for spatial autocorrelation in the structure of the scavenger assemblages, we added a spatial autocovariate term. The autocovariate term was computed from the weighted average distance of all samples, indicating the degree of spatial clustering among dependent variables. We used the 'autocov_dist' function from the 'spdep' library (Bivand 2015).
We first evaluated if the covariates affected the structure of the scavenger assemblage. We tested the effect of five covariates: two variables associated with the experimental design and study site: (a) carcass weight and (b) presence of obligate scavengers; two variables related to the network metrics: (c) matrix size and (d) matrix connectance, and one variable to account for the spatial autocorrelation of the data: (e) spatial autocovariance. To do so, we fitted one-predictor generalized linear models (GLMs) relating the covariates with the network metrics (see results of this analysis in Supplementary material Appendix 2 Table A2.2). Variables that were significantly related $(p<0.05)$ to scavenger assemblage structure were included as covariates in the models performed with the macroecological variables (see below).

Relationships between network structure and predictor variables may be non-linear and thus we compared linear and quadratic one-predictor models for each macroecological variable and our dependent variables using an AIC-based model selection approach. We determined whether each macroecological predictor variable should be included as quadratic in the models for assemblage structure (i.e. temperature seasonality for rNODF and both temperature seasonality and temperature for rWNODF).

We then evaluated the relationships between the structure of the scavenger assemblage given by each of our two network metrics (i.e. rNODF and rWNODF) and the six macroecological variables measuring climatic conditions, productivity and human impact (Table 2) by means of GLMs. To do so, we first estimated correlations among the predictor variables to identify highly correlated ones. Since none were highly correlated ( $\mathrm{r}<0.7$ in all cases), we included all variables in the analyses. Then, we calculated variance inflation factors (VIF) for the macroecological predictor variables using the 'car' package (Fox and Weisberg 2011) to further assess collinearity. The only variable exhibiting VIF values exceeding three (Zuur et al. 2010) was eliminated from the model (i.e. temperature seasonality for the two metrics). In each model, predictor variables were standardized to the same scale (i.e. they were transformed to have a mean of 0 and standard deviation of 1) and matrix size was log-transformed to meet normality. We also looked for influential outliers using the 'car' package. We detected one outlier in the model for rNODF (a dataset with small-sized birds from USA, ID $=13$, in Supplementary material Appendix 1) and we thus ran the analysis with and without it for comparison.

We fitted all possible combinations and subsets of the predictor variables and the significant covariates for each of the two network metrics separately. We selected the model with the lowest AICc, but when there was more than one model with a $\triangle \mathrm{AICc}<2$ relative to the best model, we implemented a model-averaging function in the 'MuMIn' package (Bartoń 2013). This function averages parameter estimates across all considered models for each dependent variable where the respective parameter appeared, weighted by the relative importance of each model. We also calculated the percentage of explained deviance (i.e. the amount of variability 


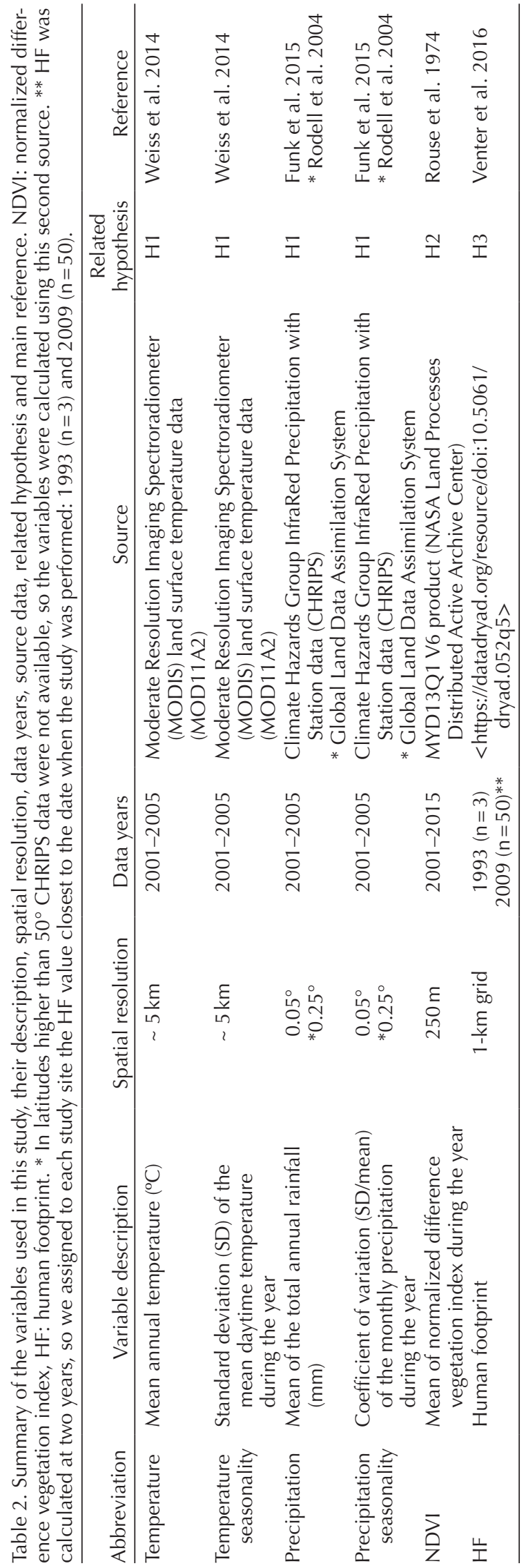

explained) of each model. We estimated the relative importance of each predictor variable $(w)$ by summing the AIC weights across all models in the set where a given variable occurred. Finally, we re-ran all the models including only the data taken using camera traps to account for differences in sampling methodology in the results.

We tested if assemblage structure was related to its scavenging function by fitting GLMs with rNODF or rWNODF values as response variables and carcass consumption rate as a predictor variable. We also included the significant covariates in the model. Consumption rate was log-transformed. We used a Gaussian distribution of errors for all GLM analyses. All analyses were performed in R 3.5.2 (R Development Core Team).

\section{Results}

Across all studies, nestedness (rNODF) values were generally positive, with only three negative values (mean $\mathrm{rNODF} \pm \mathrm{SD}$ : $1.08 \pm 0.71$; range: -0.71 to 2.90 , Supplementary material Appendix 1), suggesting scavenger assemblages are generally organized in a nested pattern. However, there was not a clear structural trend for weighted nestedness (mean $\mathrm{rWNODF} \pm \mathrm{SD}:-0.10 \pm 0.46$, range: $-1.00,1.06$ ), as this index presented a similar proportion of both positive and negative values. Also, rNODF and rWNODF were positively correlated (GLM, coefficient: 1.085, p <0.001, R²: 0.5143; Supplementary material Appendix 2 Fig. A2.1).

All the macroecological variables were highly correlated at the three spatial scales studied (all $r>0.87$, all $\mathrm{p}<0.0001$; Supplementary material Appendix 2 Table A2.1) indicating little effect of the spatial scale. Thus, we used the $20 \mathrm{~km}$ scale for all our analyses.

From the covariates assessed, both rWNODF and rNODF were related to the weight of the monitored carcasses, but none of the metrics were related to the spatial autocovariance or the presence of obligate scavengers (Fig. 3, Supplementary material Appendix 2 Table A2.2). Carcass weight affected the structure of scavenger assemblages by increasing nestedness. Also, when we evaluated the effect of the covariates associated to network properties, both nestedness metrics were related to network connectance and matrix size. Whereas network connectance decreased nestedness, larger matrices were more nested (Fig. 3, Supplementary material Appendix 2 Table A2.2).

Contrary to our Hypothesis I, most of the variables describing climatic conditions (i.e. mean temperature, temperature seasonality and precipitation seasonality) did not affect the structure of scavenger assemblages. Only precipitation was negatively related with nestedness, but this relationship was not significant after one influential outlier with a very low nestedness was removed (ID $=13$ in Supplementary material Appendix 1), or when we excluded studies based on observations (Supplementary material Appendix 2 Table A2.3-A2.5). However, our Hypothesis II was supported by the data, since assemblages in areas with higher NDVI (i.e. considered a proxy of productivity) values were more 


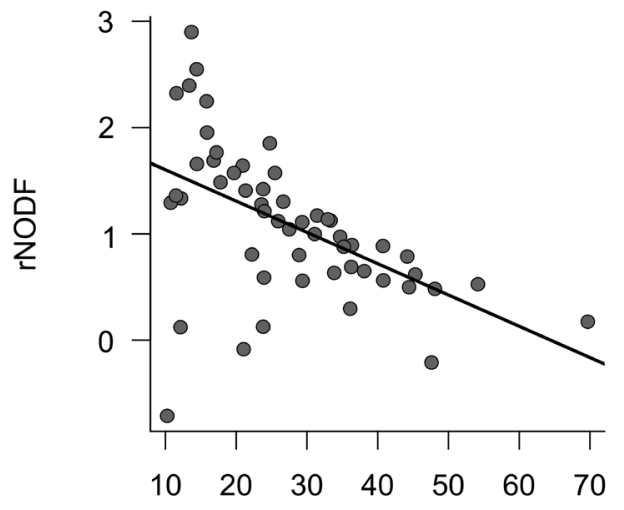

Connectance
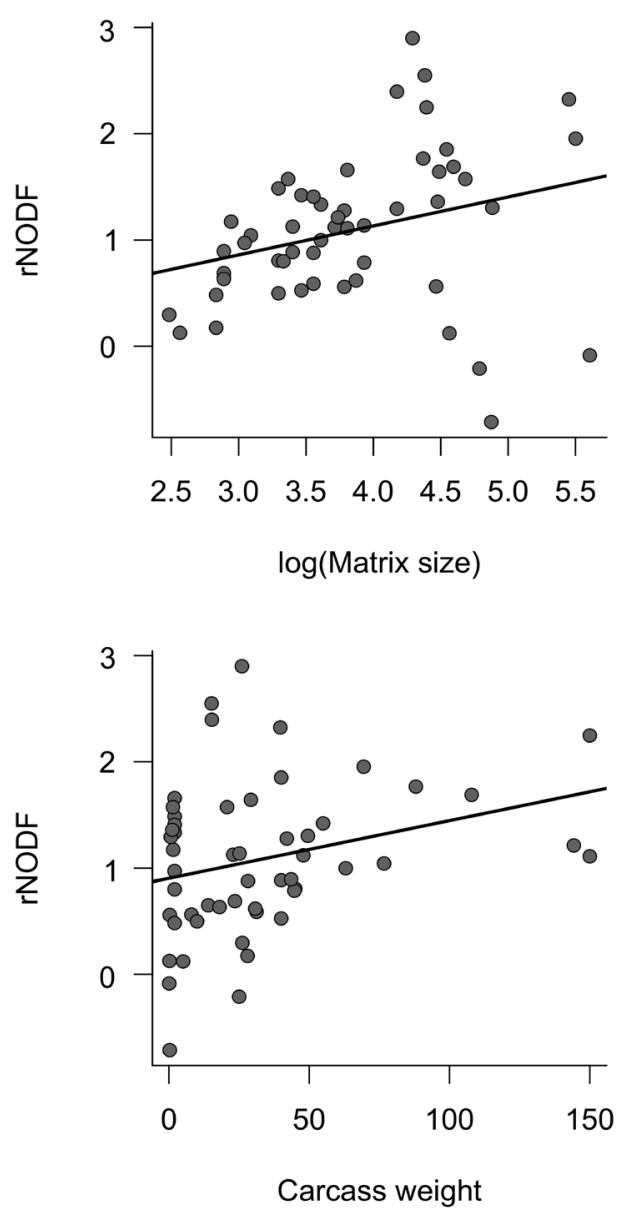

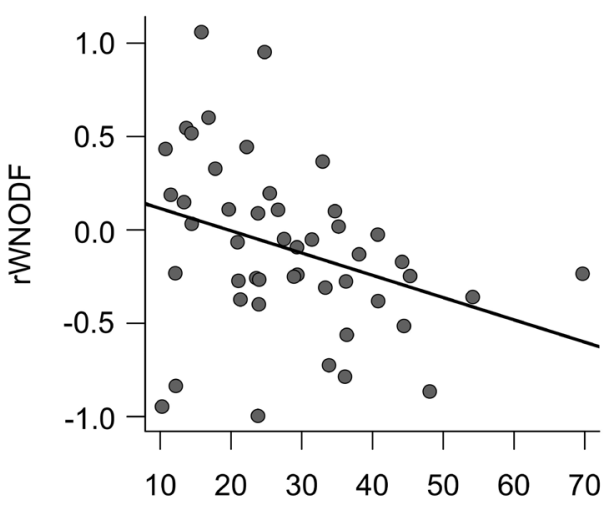

Connectance
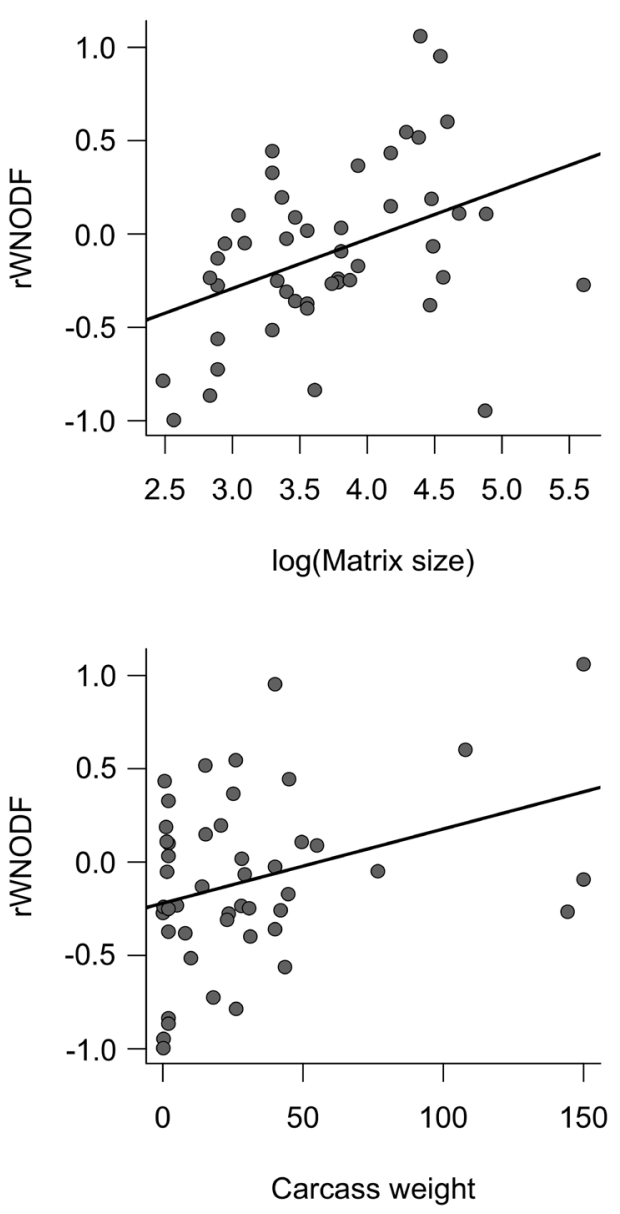

Figure 3. Graphs showing the significant univariate relationships between the covariates used in the models performed in this study and the network metrics describing nestedness (rNODF) and weighted nestedness (rWNODF). We also present the linear regression between the two variables. See Supplementary material Appendix 2 Table A2.2 for the results of the models.

nested (Table 3, Fig. 4). Also, assemblages showed a less nested structure in regions with greater human impact (i.e. areas with higher human footprint scores; Table 3, Fig. 4). Nevertheless, the relationship between network structure and some macroecological factors, especially precipitation, was weak overall and the data showed a large dispersion (see raw data in Fig. 4). None of our hypotheses were corroborated with the weighted nestedness metrics (Table 4). Finally, carcass consumption rate was positively related to both $\mathrm{rNODF}$ and marginally to rWNODF, suggesting that more organized assemblages are also functionally more efficient at consuming carcasses (Table 5). 
Table 3. Model (GLM) relating nestedness (rNODF) with macroecological variables. We present the model-averaged coefficients, standard error (SE) and the relative importance of each variable $(w)$ for models with $\Delta$ AICc $<2$. Significant $p$-values $(<0.05)$ are highlighted in bold. NDVI: normalized difference vegetation index. This model does not include the influential outlier found in the analysis (see Supplementary material Appendix 2 Table A2.3 for results including the outlier). Percentage of explained deviance of the model (i.e. proportion of the variability explained by the model): 46.33. Number of studies included in the model: 53 .

\begin{tabular}{|c|c|c|c|c|c|}
\hline Hypothesis & Variable & Coefficient & SE & w & $\mathrm{p}$-value \\
\hline Covariate & Connectance & -0.395 & 0.066 & 1.00 & $<0.001$ \\
\hline Covariate & Carcass weight & 0.065 & 0.070 & 0.23 & 0.372 \\
\hline I & Precipitation & -0.186 & 0.091 & 1.00 & 0.045 \\
\hline II & NDVI & 0.305 & 0.091 & 1.00 & 0.001 \\
\hline III & Human footprint & -0.153 & 0.069 & 1.00 & 0.031 \\
\hline
\end{tabular}

\section{Discussion}

We found that the network structure of scavenger assemblages was affected by global-scale anthropic and environmental factors. As predicted by our Hypotheses II and III, NDVI (as a proxy of biomass and productivity) and human footprint (as a proxy of degree of human impact) affected assemblage nestedness the most, while the direct effect of climatic variables on assemblage structure (Hypothesis I) had low statistical support. This suggests that both anthropogenic disturbance and environmental factors are important drivers of the network structure of vertebrate scavengers. There is growing evidence that human impact affects the structure of trophic networks, as already detected for several taxonomic groups, including terrestrial mammals (Mendoza and Araújo 2019), diatoms in lakes (Wang et al. 2019) and reef fish (Ruppert et al. 2018). Our study broadens this result to the functional group of scavengers, revealing detrimental effects for its functioning and subsequent ability to provision ecosystem services. In particular, we found that nested structure was associated with higher consumption efficiency, relating assemblage structure with its function in the ecosystem (e.g. see Bannar-Martin et al. 2017 for other networks).

NDVI was the main variable affecting assemblage structure. Previous studies showed that a nested structure minimizes competition and allows more species to coexist on the carrion resource (Selva and Fortuna 2007, SebastiánGonzález et al. 2016), and that assemblages in highly productive regions tend to have a larger number of species (Bailey et al. 2004, Cusens et al. 2012). Thus, the high competition for resources in species-rich assemblages may be compensated by a nested organization. Among scavengers, nestedness may arise from inter-specific facilitation processes, which increase the efficiency of carrion consumption. For example, some species are better able than others to locate carcasses and can be used as resource indicators (e.g. mammalian scavengers watching alighting vultures; Kane and Kendall 2017), whereas others are able to open thick skins and provide access to the nutrition-rich interior of carcasses (e.g. large scavengers opening carcasses for small scavengers, Álvarez et al. 1976). These facilitation processes occur more often in species-rich productive environments (Hooper et al. 2005, Loreau and de Mazancourt 2013) and likely promote species persistence (Sebastián-González et al. 2016) and efficient nutrient cycling (Mateo-Tomás et al. 2017).

Another factor that affected the structure of vertebrate scavenger assemblages was human impact. Recently, the number of vertebrate scavenger species observed at carcasses was shown to decrease with higher anthropogenic disturbance (SebastiánGonzález et al. 2019). Our results suggest that anthropogenic disturbance also affects the way species are organized in the scavenger assemblage. The most nested scavenger assemblages were found in relatively pristine regions, such as Bialowieza Forest (Poland), whereas the most random assemblages were present in regions most impacted by human activities, such as in areas close to large cities (Fig. 3). Species-rich assemblages retaining the most efficient carrion consumers (e.g. vultures and large mammals; Dirzo et al. 2014, Mateo-Tomás et al. 2017) are strongly nested (Selva and Fortuna 2007), whereas the extirpation of these species breaks down this structure. It seems that defaunated assemblages lack the facilitation processes provided by key scavengers, reducing assemblage robustness to high levels of interspecific competition for carrion (Sebastián-González et al. 2016). The fact that vulture presence did not generally influence the degree of nestedness indicates that vultures are not the only key scavengers affecting scavenger assemblages in terrestrial ecosystems. Other species such as large carnivores also seem to be efficient scavengers (Moleón et al. 2015, Mateo-Tomás et al. 2017). In addition, some 'facilitatory' species, such as large predators (Moleón et al. 2014) could be especially vulnerable to human disturbance. Thus, further studies should try to identify the traits that characterize these key species, to uncover the most appropriate management strategies aiming to preserve the ecosystem functions provided by scavengers (Buechley and Şekercioğlu 2016).

Besides the effect of species loss, human-impacted regions may provide persisting scavengers with an increased availability of alternative foods through anthropic subsidies (MorenoOpo and Margalida 2019), reducing competition for carrion (Oro et al. 2013). In these humanized regions, facilitation processes lose their relevance and scavenger assemblages may be more randomly organized. Moreover, the effects of humanrelated disturbances are expected to increase where human populations continue to grow (United Nations 2019), threatening the maintenance of ecosystem functions and services provided by scavengers (DeVault et al. 2016). The metric 

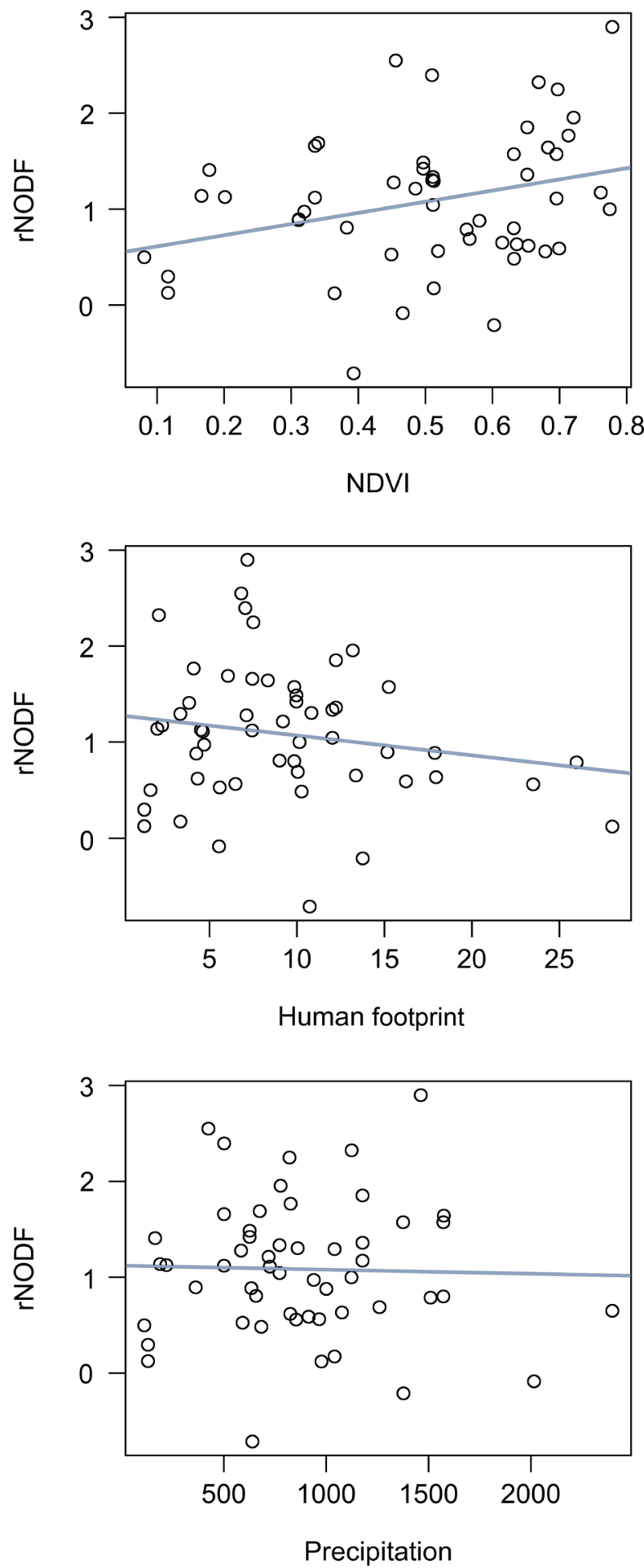

Figure 4. Relationships between the network metric nestedness (rNODF) and the significant macroecological variables. NDVI: normalized difference vegetation index. The line shows the relationship between the two variables predicted by the multivariate model in Table 3 and the dots represent real data.

used to measure human impact (HF) is based on a combination of information on population density, infrastructure and human access. That provides a good general descriptor of anthropogenic disturbance but does not permit the identification of specific factors affecting scavenger assemblages. Such factors could include poisoning of carcasses for retaliatory killing of predators (Ogada et al. 2019) or the use of veterinary drugs such as diclofenac (Green et al. 2016). Thus, we recommend further studies to determine the relative importance of specific anthropic drivers affecting the structure of scavenger assemblages (Buechley and Şekercioğlu 2016).

The nested organization of the assemblage was also related to faster carrion consumption rate. This relationship has already been detected for five Spanish sites (SebastiánGonzález et al. 2016), but this is the first time that it has been recorded at a global scale. Our results support the view that nestedness is driven by facilitation processes among the species that consequently increase carrion consumption efficiency (Selva and Fortuna 2007, Sebastián-González et al. 2016). Moreover, the negative effect of human activities on assemblage structure will also reduce the efficiency in the provisioning of scavenging functions by scavenger species, with important implications for the functioning of the ecosystem and the services it provides. However, further research is needed to explore the comparative influence of assemblage attributes, such as composition and structure, and other external factors on scavenging efficiency of different carcass types and sizes. These studies should consider finer estimates of consumed carrion biomass and additional efficiencyrelated metrics, such as carcass detection time.

Our prediction that the structure of scavenger assemblages would be directly related to climatic conditions was not supported by the analyses. Although mean annual rainfall was negatively correlated with nestedness, the effect was weak and the variability large (Fig. 4). Climatic conditions can affect food availability and thus competition for carrion resources (Selva and Fortuna 2007, Sebastián-González et al. 2016), but other non-climatic factors such as productivity and human impact seem to be more important drivers of assemblage structure. Also, climate may indirectly affect the structure of scavenger assemblages through its effects on NDVI values (Pei et al. 2019). Moreover, we focused on vertebrate scavengers because they rapidly consume large amounts of carrion (e.g. > 90\% carrion available, DeVault et al. 2011), particularly during colder months. However, at high temperatures decomposers become strong competitors and can monopolize some carcasses (DeVault et al. 2011, Ray et al. 2014), thereby influencing the organization of the vertebrate scavenger assemblage.

Interestingly, the weighted metric of nestedness showed weaker trends than the one based on occurrences. Even if both metrics were significantly related, weighted nestedness was not related to any macroecological variable and did not support any of our hypotheses. This may be partially related to the methodology used to quantify the number of individuals consuming a carcass, which underestimates the abundance of those species that do not have distinct marks, color patterns, age/sexual dimorphism, or are solitary foragers and thus rarely gather at carcasses. Thus, there may be geographical differences in the relative abundances depending on 
Table 4. Model (GLM) relating the weighted nestedness (rWNODF) with macroecological variables. We present the model-averaged coefficients, standard error $(\mathrm{SE})$ and the relative importance of each variable $(w)$ for models with $\triangle \mathrm{AICc}<2$. Significant $\mathrm{p}$-values $(<0.05)$ are highlighted in bold. Temperature^ 2 represents the quadratic term of the Temperature variable. NDVI: normalized difference vegetation index. Percentage of explained deviance of the model (i.e. proportion of the variability explained by the model): 37.72 . Number of studies included in the model: 47.

\begin{tabular}{|c|c|c|c|c|c|}
\hline Hypothesis & Variable & Coefficient & SE & w & p-value \\
\hline Covariate & Connectance & -0.120 & 0.069 & 0.503 & 0.091 \\
\hline Covariate & Carcass weight & 0.138 & 0.062 & 1.00 & 0.031 \\
\hline Covariate & Log (matrix size) & 0.146 & 0.071 & 0.73 & 0.043 \\
\hline I & Temperature ${ }^{\wedge} 2$ & 0.080 & 0.061 & & 0.208 \\
\hline I & Precipitation & 0.094 & 0.067 & 0.22 & 0.165 \\
\hline I & Precipitation seasonality & 0.063 & 0.059 & 0.06 & 0.308 \\
\hline
\end{tabular}

Table 5. Models (GLM) relating nestedness (rNODF) or weighted nestedness (rWNODF) with carcass consumption rate (log-transformed). We present the model coefficients, standard error (SE) and the p-values. Significant p-values $(<0.05)$ are highlighted in bold.

\begin{tabular}{|c|c|c|c|c|c|}
\hline Network & Variable type & Variable & Coefficient & SE & $\mathrm{p}$-value \\
\hline \multirow[t]{3}{*}{ rNODF } & Covariate & Connectance & -0.418 & 0.091 & $<0.001$ \\
\hline & Covariate & Carcass weight & 0.025 & 0.105 & 0.816 \\
\hline & Predictor & Log (consumption rate) & 0.273 & 0.115 & 0.022 \\
\hline \multirow{3}{*}{ rWNODF } & Covariate & Carcass weight & 0.044 & 0.077 & 0.568 \\
\hline & Covariate & Log (matrix size) & 0.172 & 0.075 & 0.028 \\
\hline & Predictor & Log (consumption rate) & 0.149 & 0.084 & 0.086 \\
\hline
\end{tabular}

what species are present in the different parts of the world and if individuals of these species can be easily identified. Moreover, weighted nestedness is less prevalent in ecological assemblages than nestedness (Sebastián-González et al. 2015) because it requires that both the assemblage and its weights (here, relative abundances) are nested (Almeida-Neto and Ulrich 2011). Indeed, in this study, the mean rWNODF value was close to zero, suggesting that vertebrate scavenger assemblages do not follow a weighted nested pattern and thus a lack of macroecological trends is not surprising.

Finally, it is important to underline that the effects of some of the variables were weak and the data were highly variable. This reflects the complexity of scavenger systems across the globe and the challenges of making predictions about the effects of human development and climate change on their structure. That said, our dataset is the largest ever compiled and analyzed for vertebrate scavengers, and included a wide variety of arid and mesic terrestrial ecosystems distributed across temperate and tropical regions, making our results representative of a large diversity of scavenger assemblages around the world. We show for the first time that the network structure of scavenger assemblages is affected by global-scale factors such as the degree of human impact (i.e. HF), a combination of ecosystem productivity and biomass (i.e. NDVI) and nestedness increases scavenger efficiency, an important ecological function and ecosystem service. These findings can help to inform global conservation planning aimed at maintaining the essential ecosystem functions provided by vertebrate scavengers in terrestrial ecosystems.

\section{Data availability statement}

All data necessary to reproduce the analyses presented in this study are included in the Supplementary material Appendix 1 and available from Figshare Digital Repository: <https:// doi.org/10.6084/m9.figshare.12179880.v1> (SebastiánGonzález et al. 2020).

Acknowledgements - ALB and JDA would like to thank the Edmund Niles Huyck Preserve, Lyme Adirondack Forest Company and LandVest Timberland. EP, YA, HU and DV completed study under research permit by The Republic of Turkey Ministry of Agriculture and Forestry. We also thank four anonymous reviewers for their constructive comments.

Funding - ESG, JMB and JMPG were supported by Juan de la Cierva contracts (Ministerio de Economía y Competitividad, MEC; IJCI-2015-24947, IJCI-2017-32149 and FJCI-2015-25632, respectively). ESG and LNA were also supported by Generalitat Valenciana (SEJI/2018/024 and ACIF/2019/056, respectively), ACA by the Govern de les Illes Balears (PD/039/2017) and MM by a Ramón y Cajal contract (MEC; RYC-2015-19231). EA was supported by La Caixa-Severo Ochoa International PhD Program 2015, ZMR by a postdoctoral contract co-funded by the Generalitat Valenciana and the European Social Fund (APOSTD/2019/016). NS was partly supported by the National Science Centre in Poland (2013/08/M/NZ9/00469 and 2016/22/Z/NZ8/00). SAL thanks PICT (BID) 0725/2014. MK and KJ were supported by the Slovenian Research Agency (P4-0059) and EU Life DinAlp Bear (LIFE13 NAT/SI/000550). Contributions of HG, KLT, EFA, OER, TLD and JCB were partially supported through funding 
from U.S. Dept of Agriculture and the U.S. Dept of Energy under (DE-EM0004391) to the Univ. of Georgia Research Foundation. HG was also supported by the Inst. of Environmental Radioactivity at Fukushima Univ. ALB and JDA were partially supported by Queens College and the Graduate Center at the City Univ. of New York. JDA is currently supported by a Ramón y Cajal contract (RYC-2017-22783) co-funded by the Spanish Ministry of Science, the Agencia Estatal de Investigación and the European Social Fund. ERB and EF were supported by the USA National Science Foundation Graduate Research Fellowship (1256065). CK completed study with support from Hawk Mountain Sanctuary, The Peregrine Fund, and via Pompeo M. Maresi Memorial Fund via Princeton Univ. JAS and CCW were supported by the USA National Science Foundation \#1255913, the American Association for Univ. Women and the Gordon and Betty Moore Foundation. HUW acknowledges funding from the California Dept of Fish and Wildlife (P0880013). PLP was supported by the Rufford Foundation and Univ. of Wisconsin-Madison. JB and JdT thank the Percy Sladen Memorial Fund and Mr Rodney Fuhr. Several authors were funded by funds from the MEC (CGL201240013-C02-01/02, CGL2015-66966-C2-1-R, CGL2015-66966C2-1-R2, CGL2017-89905-R and RTI2018-099609-B-C22) and from the Junta de Andalucía (RNM-1925). POV was supported by a research contract by the Univ. of Lleida. ES and TMN were funded and supported by Australian Geographic, Bush Heritage Australia, Australian Academy of Sciences, Ecological Society of Australia, NSW Office of Environment and Heritage, and Emirates Wolgan Valley One and Only Resort.

Author contributions - ESG and JASZ designed the research; each author/s collected the data from their site (see Supplementary material Appendix 1); ESG performed the analyses and led the writing; all authors read and revised the manuscript.

\section{References}

Albouy, C. et al. 2019. The marine fish food web is globally connected. - Nat. Ecol. Evol. 3: 1153-1161.

Allen, M. L. et al. 2014. Trophic facilitation or limitation? Comparative effects of pumas and black bears on the scavenger community. - PLoS One 9: e102257.

Almeida-Neto, M. and Ulrich, W. 2011. A straightforward computational approach for measuring nestedness using quantitative matrices. - Environ. Model. Softw. 26: 173-178.

Almeida-Neto, M. et al. 2008. A consistent metric for nestedness analysis in ecological systems: reconciling concept and measurement. - Oikos 117: 1227-1239.

Álvarez, F. et al. 1976. Interactions among avian scavengers in southern Spain. - Ornis Scand. 7: 215-226.

Bailey, S.-A. et al. 2004. Primary productivity and species richness: relationships among functional guilds, residency groups and vagility classes at multiple spatial scales. - Ecography 27: 207-217.

Bannar-Martin, K. H. et al. 2017 Integrating community assembly and biodiversity to better understand ecosystem function: the community assembly and the functioning of ecosystems CAFE approach. - Ecol. Lett. 21: 167-180.

Bartoń, K. 2013. MuMIn: multi-model inference. - R package ver. 1.9.5, <http://CRAN.Rproject.org/package=MuMIn>.

Bascompte, J. and Jordano, P. 2013. Mutualistic networks. Monographs in population biology. - Princeton Univ. Press.
Beasley, J. C. et al. 2019 Ecological functions of vertebrate scavenging. - In: Olea, P. P. et al. (eds), Carrion ecology and management. Wildlife research monographs. Springer, pp. 125-157.

Bivand, R. 2015. Spatial dependence: weighting schemes, statistics and models. - <https://cran.r-project.org/web/packages/spdep/ spdep.pdf $>$.

Buechley, E. R. and Şekercioğlu, Ç. H. 2016. The avian scavenger crisis: looming extinctions, trophic cascades and loss of critical ecosystem functions. - Biol. Conserv. 198: 220-228.

Cusens, J. et al. 2012. What is the form of the productivity-animal-species-richness relationship? A critical review and metaanalysis. - Ecology 93: 2241-2252.

Dalsgaard, B. et al. 2013. Historical climate-change influences modularity and nestedness of pollination networks. - Ecography 36: 1331-1340.

de Miguel, J. M. et al. 2016. Non-random co-occurrence of native and exotic plant species in Mediterranean grasslands. - Acta Oecol. 77: 18-26.

DeVault, T. L. et al. 2004. Factors influencing the acquisition of rodent carrion by vertebrate scavengers and decomposers. - Can. J. Zool. 82: 502-509.

DeVault, T. L. et al. 2011. Mesopredators dominate competition for carrion in an agricultural landscape. - Basic Appl. Ecol. 12: $268-274$.

DeVault, T. L. et al. 2016. Ecosystem services provided by avian scavengers. - In: Şekercioğlu, C. H. et al. (eds), Why birds matter: avian ecological function and ecosystem services. Univ. of Chicago Press, pp. 235-270.

Dirzo, R. et al. 2014. Defaunation in the Anthropocene. - Science 345: 401-406.

Dormann, C. F. et al. 2009. Indices, graphs and null models: analyzing bipartite ecological networks. - Open J. Ecol. 2: 7-24.

Fortuna, M. A. et al. 2010 Nestedness versus modularity in ecological networks: two sides of the same coin? - J. Anim. Ecol. 79: 811-817.

Fox, J. and Weisberg, S. 2011. An R companion to applied regression, 2nd ed. - Sage Publications.

Funk, C. et al. 2015. The climate hazards infrared precipitation with stations - a new environmental record for monitoring extremes. - Sci. Data 2: 150066.

Green, R. E. et al. 2016 Potential threat to Eurasian griffon vultures in Spain from veterinary use of the drug diclofenac. - J. Appl. Ecol. 53: 993-1003.

Guillemot, N. et al. 2011. Functional redundancy patterns reveal non-random assembly rules in a species-rich marine assemblage. - PLoS One 610: e26735.

Hooper, D. U. et al. 2005. Effects of biodiversity on ecosystem functioning: a consensus of current knowledge. - Ecol. Monogr. 75: 3-35

Huijbers, C. M. et al. 2015. Limited functional redundancy in vertebrate scavenger guilds fails to compensate for the loss of raptors from urbanized sandy beaches. - Divers. Distrib. 21: 55-63.

Kane, A. and Kendall, C. J. 2017. Understanding how mammalian scavengers use information from avian scavengers: cue from above. - J. Anim. Ecol. 86: 837-846.

Landi, P. et al. 2018. Complexity and stability of ecological networks: a review of the theory. - Popul. Ecol. 60: 319-345.

Ley, R. E. et al. 2017. Ecological and evolutionary forces shaping microbial diversity in the human intestine. - Cell 124: $837-848$. 
Loreau, M. and de Mazancourt, C. 2013. Biodiversity and ecosystem stability: a synthesis of underlying mechanisms. - Ecol. Lett. 16 (Suppl. 1): 106-115.

Martín-González, A. M. et al. 2015. The macroecology of phylogenetically structured hummingbird-plant networks. - Global Ecol. Biogeogr. 24: 1212-1224.

Mateo-Tomás, P. et al. 2017. Both rare and common species support ecosystem services in scavenger communities. - Global Ecol. Biogeogr. 26: 1459-1470.

Mendoza, M. and Araújo, M. B. 2019. Climate shapes mammal community trophic structures and humans simplify them. - Nat. Commun. 10: 5197.

Moleón, M. et al. 2014. Inter-specific interactions linking predation and scavenging in terrestrial vertebrate assemblages. - Biol. Rev. 89: 1042-1054.

Moleón, M. et al. 2015. Carcass size shapes the structure and functioning of an African scavenging assemblage. - Oikos 124: 1391-1403.

Montesinos-Navarro, A. et al. 2017. Network structure embracing mutualism-antagonism continuums increases community robustness. - Nat. Ecol. Evol. 1: 1661-1669.

Morales-Reyes, Z. et al. 2015. Supplanting ecosystem services provided by scavengers raises greenhouse gas emissions. - Sci. Rep. 5: 7811 .

Moreno-Opo, R. and Margalida, A. 2019. Human-mediated carrion: effects on ecological processes. - In: Olea, P. P. et al. (eds), Carrion ecology and management. Wildlife research monographs. Springer, pp. 183-212.

Ogada, D. et al. 2019 What makes carrion unsafe for scavengers? Considerations for appropriate regulatory policies and sound management practices. - In: Olea, P. P. et al. (eds), Carrion ecology and management. Wildlife research monographs. Springer, pp. 213-242.

Oro, D. et al. 2013. Ecological and evolutionary implications of food subsidies from humans. - Ecol. Lett. 16: 1501-1514.

Pei, Z. et al. 2019. The relationship between NDVI and climate factors at different monthly time scales: a case study of grasslands in inner Mongolia, China (1982-2015). - Sustainability 11: 7243 .

Ray, R. R. et al. 2014. Invertebrates outcompete vertebrate facultative scavengers in simulated lynx kills in the Bavarian Forest National Park, Germany. - Anim. Biodivers. Conserv. 371: 77-88.

Rodell, M. et al. 2004. The global land data assimilation system. - Bull. Am. Meteorol. Soc. 85: 381-394.

Rouse, J. W. et al. 1974. Monitoring vegetation systems in the Great Plains with ERTS. - In: Third ERTS symposium, NASA SP-351. Washington D.C., pp. 309-317.

Supplementary material (available online as Appendix ecog05083 at <www.ecography.org/appendix/ecog-05083>). Appendix 1-2.
Rovero, F. and Zimmermann, F. 2016. Camera trapping for wildlife research. - Pelagic Publishing.

Ruppert, J. L. W. et al. 2018. Human activities as a driver of spatial variation in the trophic structure of fish communities on Pacific coral reefs. - Global Change Biol. 24: e67-e76.

Schleuning, M. et al. 2014. Ecological, historical and evolutionary determinants of modularity in weighted seed-dispersal networks. - Ecol. Lett. 17: 454-463.

Sebastián-González, E. et al. 2015. Macroecological trends in nestedness and modularity in seed-dispersal networks: human impact matters. - Global Ecol. Biogeogr. 24: 293-303.

Sebastián-González, E. et al. 2016. Nested species-rich networks of scavenging vertebrates support high levels of interspecific competition. - Ecology 97: 95-105.

Sebastián-González, E. et al. 2019. Scavenging in the Anthropocene: human impact drives vertebrate scavenger species richness at a global scale. - Global Change Biol. 25: 3005-3017.

Sebastián-González, E. et al. 2020. Data from: Network structure of vertebrate scavenger assemblages at the global scale: drivers and ecosystem functioning implications. - Figshare Digital Repository, <https://doi.org/10.6084/m9.figshare.12179880.v1>.

Selva, N. and Fortuna, M. A. 2007. The nested structure of a scavenger community. - Proc. R. Soc. B 274: 1101-1108.

Selva, N. et al. 2005. Factors affecting carcass use by a guild of scavengers in European temperate woodland. - Can. J. Zool. 83: $1590-1601$.

Song, C. et al. 2017. Why are some plant-pollinator networks more nested than others? - J. Anim. Ecol. 86: 1417-1424.

Turner, K. et al. 2017. Abiotic and biotic factors modulate carrion fate and vertebrate scavenging communities. - Ecology 98: 2413-2424.

Tylianakis, J. M. et al. 2010. Conservation of species interaction networks. - Biol. Conserv. 143: 2270-2279.

United Nations 2019. World population prospects 2019: highlights ST/ESA/SER.A/423. - Dept of Economic and Social Affairs, Population Division.

Venter, O. et al. 2016. Sixteen years of change in the global terrestrial human footprint and implications for biodiversity conservation. - Nat. Commun. 7: 12558.

Verhoef, H. A. and Morin, P. J. 2010. Community ecology. - Oxford Univ. Press.

Wang, R., et al. 2019. Network parameters quantify loss of assemblage structure in human-impacted lake ecosystems. - Global Change Biol. 25: 3871-3882.

Weiss, D. J. et al. 2014. An effective approach for gap-filling continental scale remotely sensed time-series. - ISPRS J. Photogramm. Remote Sens. 98: 106-118.

Zuur, A. F. et al. 2010. A protocol for data exploration to avoid common statistical problems. - Methods Ecol. Evol. 1: 3-14. 